\title{
ACHIEVING EXCELLENCE IN LEAN IMPLEMENTATION AT CONSTRUCTION COMPANIES - A CASE STUDY FROM BRAZIL
}

\author{
Caroline P. Valente ${ }^{1}$, Carlos Alexandre M. do A. Mourão², Angela de B. Saggin ${ }^{3}$, \\ José de P. Barros Neto ${ }^{4}$, and Jorge M. da Costa ${ }^{5}$
}

\begin{abstract}
Lean Construction has become a popular concept to improve performance and reduce costs in construction projects. Assessment tools and implementation strategies that focus on lean practices such as the Last Planner ${ }^{\circledR}$ System, the use of Kanbans, the routine of Kaizens and, recently, the integration with information technology are also common. However, barriers to the wide adoption of lean principles remain and implementation challenges continue to intrigue scholars. Previous studies suggest that barriers to the successful implementation can be either political, economical, social and/or technical, with the focus on lack of knowledge about lean concepts, resistance to the required organisational culture change, and lack of support from top management. Few studies present the lean implementation process from the practitioners' perspective. Using the narrative enquiry methodology, the authors aim to describe how a construction company from Brazil matured from the implementation of lean operational tools to achieve excellence in the lean culture and mindset. Key themes that emerge from this study for a successful lean construction journey are; effort to stabilise the environment, knowledge creation and management, transparency in the process to enable simplicity and shared understanding, and building trust for further growth.
\end{abstract}

\section{KEYWORDS}

Lean construction, lean culture, lean implementation, commitment, enactment.

\section{INTRODUCTION}

Even though lean construction has become an increasingly popular concept to improve performance and reduce costs in construction projects, barriers to the wide adoption of

1 PhD Candidate, Civ. Eng., MSc, School of Built Environment, Univ. of Technology Sydney, Australia, carolinevalente@gmail.com, orcid.org/0000-0002-8539-8200

2 PhD Candidate, Civ. Eng. M.Sc., Fac. of Engin., Univ. of Porto, Technical Director, C. Rolim Engenharia, Fortaleza, Brazil, alexandre@crolim.com.br, orcid.org/0000-0001-9711-970X

3 Civ. Eng. MBA, Technical Manager, C. Rolim Engenharia, Fortaleza, Brazil, angela@crolim.com.br, orcid.org/0000-0002-7166-8556

4 Professor, Dept. of Acad. and Technol. Integ., Fed. Univ. of Ceará, Fortaleza, Brazil, jpbarros@ufc.br, orcid.org/0000-0001-5131-4593

5 Assoc. Professor, Faculty of Engineering, University of Porto, Portugal, imfcosta@fe.up.pt, orcid.org/0000-0002-7128-2952 
lean principles remain and implementation challenges continue to intrigue scholars. Some argue that the existing literature is too prescriptive, neglecting the social and dynamic nature of the implementation process (Bygballe and Swärd 2014). Others claim it is still necessary to further develop the lean construction vocabulary and improve concepts and definitions, avoiding ambiguities in practice (Green and May 2005). Overall, lack of experience, lack of long-term lean philosophy, and lack of understanding of lean construction terms jeopardise a successful lean practice by construction companies (Demirkesen et al. 2019).

Ultimately, it is crucial for researchers to realise lean construction is not a 'ready-touse' concept nor its implementation follows a 'one-size-fits-all' approach (Pekuri et al. 2012). The lean implementation process is "representative of social, financial and cultural contexts that seek to provide implementation bias representative of misconceptions without acknowledgement of the true lean journey" (Chesworth 2015 p. 623). The cultural and other 'soft' aspects of lean implementation have been researched more recently, culminating in the understanding of lean as a "creative ethic", rather than just a scientific method applied to work (Richert and McGuffey 2019).

Additionally, the majority of published lean construction implementation papers are based on scholars' or consulting companies' perspectives and interpretations of isolated lean tools' implementations (Arbulu et al. 2007; Kalyan et al. 2018). Few are written by the own companies or include the practitioners' views to account on the true obstacles of the lean journey (Barbosa et al. 2013; Bygballe and Swärd 2014). In this sense, an important component, the role of agency in lean implementation, is often disregarded.

To facilitate the dissemination of lean procedures and techniques, many lean construction assessment tools, maturity models and implementation strategies have been developed worldwide. Despite the importance of these evaluative or prescriptive systems in supporting the continuous improvement process and benchmarking, the focus on isolated lean tools or subjective assessments do not necessarily assist in implementation strategies (Rodegheri and Serra 2019).

Therefore, through a qualitative research approach, this study aims to answer the following research question: How to mature from the implementation of isolated lean operational tools to a successful lean culture and mindset? A case study of a construction company from Brazil is used to provide evidence to support findings.

\section{A REVIEW ON LEAN CONSTRUCTION IMPLEMENTATION}

Wandahl (2014) identified in his study on lean implementation that most of the existing literature is based on previous literature summaries, single or few construction projects, or on industry surveys, either interviews or questionnaires.

Only a few papers report on case studies of "real-world" implementations. Among them, a good example comes from Bygballe and Swärd (2014 p. 11), which practice perspective reveals the lean journey is an ongoing effort, "being refined and adapted to the context in which it was used, a process which never really finished". As Morrey et al. (2011) confirm, lean implementation needs to be based on adaptation theory.

Many implementation strategies have been devised to guide lean construction implementation. Kalyan et al. (2018) recommend a dual approach of building capability in the teams from the bottoms up and having management drive continuous improvements from the top down.

Pekuri et al. (2012) state that, to avoid the focus on isolated tools and properly motivate people in continuous improvement and lean mindset, it is necessary to start the 
journey with building trust, ensuring skills and competence, developing and selecting the right people, and providing leadership. Similarly, Rodegheri and Serra (2019) developed a 'legacy transformation model', which focuses on social aspects of connecting people for a shared core identity and team purpose, daily awareness of the surrounding environment, commitment, engagement and a shared meaningful goal that requires team growth.

Nesensohn et al. (2012) introduced the role of the Lean Project Manager at a strategic level and across all projects, "educating all parties involved in construction on lean thinking, principles and techniques and providing advice and guidance as to how to optimize the processes associated with lean" (Nesensohn et al. 2012 p. 8).

Later, Nesensohn (2017) created a lean construction maturity model for organizations involving the assessment of: leadership, philosophy (customer focus and way of thinking), people (culture and behaviour, competencies, improvement enablers), process and systems (processes and tools, and change), outcomes and outputs of the work environment, learning and competency development.

However, this is not a consensus. Lidelöw and Simu (2015), for example, understand lean construction as an operations strategy, outlining how operations should be conducted to support the business strategy. In this sense, they claim ten generic decision categories should be given attention when implementing lean, including process technology, facilities, organization, production control, product development, and performance measurement. As seen, there is more focus on the process rather than on people.

In fact, usually, the lean construction journey starts with the Last Planner System (Barbosa et al. 2013; Poshdar et al. 2019; Wandahl 2014), as this is a critical tool for stabilisation and production control, and failure to apply it leads to successive snowball effects and problems in other lean tools (Demirkesen et al. 2019). Later, other techniques and concepts are implemented, such as autonomation, just-in-time (JIT) concepts, production levelling, jidoka, Kanban, standardised work, and IT technologies and BIM (Kalyan et al. 2018; Li et al. 2019).

Nevertheless, it is fundamental that the company has in mind that the implementation of lean tools and techniques needs to be properly backed up with a thorough training that enables the development of a lean culture - a learning organisation that values reflecting, planning, and continuously improving with a customer-focused purpose and shared personal and collective objectives through cohesive teamwork and effective leadership (Integris Performance Advisors 2015; Liker et al. 2008).

\section{COMMON BARRIERS TO LEAN IMPLEMENTATION}

Many academic studies comment on barriers to lean implementation, most of which are related to organisational difficulties to expose the errors and learn from them (Morrey et al. 2011; Poshdar et al. 2019; Wandahl 2014). After a detailed examination of relevant literature, Demirkesen et al. (2019) identified and categorised 27 common implementation barriers into seven groups, as follows; political, economical, technical, workforce, cultural, managerial, and communication barriers.

In their study, the lack of top management support, misperception about lean practices, and lack of information sharing were the top three barriers for lean implementation among practitioners (Demirkesen et al. 2019).

Chesworth (2015) also identified some misconceptions of lean that threaten its successful implementation. These misconceptions are related to the paradox of standardisation versus the flexibility required to adapt and innovate processes, the 
common idea that lean should be driven by corporate agenda (top-down approach), and the problem of implementing lean without a clear strategic direction. All of them can be associated particularly with the political, cultural and managerial barriers described above.

Morrey et al. (2011) focus on social barriers, especially employee involvement and empowerment during the lean journey. They also discuss the challenge of "reinventing the [lean implementation] approach until it works within that organisation" (Morrey et al. 2011 p. 8). Finally, Richerty and McGuffey (2019) recommend broader research on the holistic and "soft" aspects of generating enthusiasm for lean, as they may explain how to obtain full engagement of everyone on a project team in lean practices.

\section{METHODOLOGY}

Primarily, at the role of conducting this research, the researchers acknowledge that their own experiences and understandings that are brought to the research and, which are also developed during it, are an important ingredient of the research process (Robson 2002).

Moreover, from the personal and professional background of the researchers, there is a pragmatic perspective, aimed at deriving knowledge about the 'real world' problem to provide practical solutions (Creswell and Creswell 2018). It encompasses a pluralistic approach to data collection and analysis.

Therefore, a qualitative approach is used in this study, mainly by the observational research of a case study: a construction company from Brazil. Case studies are an appropriate method for understanding the complex relationship between factors, as they operate within a particular social setting, and they also provide an in-depth account of events, experiences or processes occurring in that particular instance (Denscombe 2010). The main authors are seen as observing-participants, as they already had a position in the company before taking on the role of observers.

To triangulate different data sources and to ensure data quality, the research was organised in four steps, as follows: an initial literature search on lean construction implementation to guide and frame the conceptual analysis, extensive archival search through company's reports and publications, the writing up of the lean journey narrative of the company and, finally, comparing findings from this study with the literature of similar studies in different contexts, to improve analytical rigour.

\section{THE SETTING}

This company was chosen because the main authors have worked or work there for many years and also for being a leading company in the implementation of lean construction in Brazil, recognised with many awards by the AEC industry ${ }^{6}$ and by the benchmarking, technical visits and publications with the international lean construction community ${ }^{7}$.

Founded in 1977 at Fortaleza, North-eastern Brazil, the construction company of this case study develops and builds upper-middle-class residential as well as commercial building projects. In total, it has more than $800,000 \mathrm{~m} 2$ of constructed area and 36,000 $\mathrm{m} 2$ under construction, distributed into 3 buildings and 148 private units. The company

\footnotetext{
${ }^{6}$ It has been elected as 'Best Builder' in the state of Ceará, three times in the last four years.

7 The company had the opportunity to represent the Brazilian construction industry at the Conference of the Parties (COP 23), the largest event on Climate Change, held in Bonn (Germany) in 2017 and to present its work through research papers and technical visits at international events, such as many IGLC conferences.
} 
has about 300 employees, of which $85 \%$ per cent are construction labourers, carpenters, plumbers, etc. In the past three years, the organisation's yearly turnover varied between 2.5 and $3.5 \%$, achieving the goal of less than $5 \%$ turnover per year.

The lean journey in this company started in 2004, when its top managers attended the 1st International Seminar on Lean Construction (CONENX) in the city of Fortaleza. They realised that the lean philosophy was aligned with its management and production values and concepts of continuous improvement, product flexibility and exceeding clients' expectations. Over these sixteen years, the company has evolved from the isolated use of lean tools into a systematic lean business model.

It is argued that the company has experienced positive results from the beginning of its lean journey mainly due to the management support and its already standardised management practices, such as the Quality Management System, which was implemented in 1998 and later certified by ISO 9002. Thus, the main construction and management processes, and work instructions were well documented and audited. Likewise, the company also had some basic $5 \mathrm{~S}$ policy guidelines before 2004 , as well as some initiatives related to sustainability and social responsibility.

\section{FINDINGS}

The company's lean journey started in two strands; holistic and theoretical, as in internalising the knowledge to develop a lean culture and mindset, and practical, as in the implementation of processes and tools to stabilise production, reduce waste and improve performance. Specific information on process transparency, the lean culture formation, the 'building trust' movement are also explained.

\section{KNOWLEDGE CREATION AND MANAGEMENT}

First, right after the 2004 CONENX, all members of the technical management team (from site supervisors to directors) were encouraged to read about lean production and lean construction, and the company facilitated this education process through the acquisition of several books on the subject, creation of a free corporative library and the organisation of seminar-like events, where all readings were presented and discussed among members. From the very beginning, the company decided to establish this knowledge creating and management culture to internalise and expand the knowledge acquired in the 2004 event. To understand 'the ideas behind the tools' to be implemented later helped them to see the construction processes differently - as flow and conversion processes (Koskela 1992) - to eliminate waste and variability within them. In 2006, a Lean Coordinator was nominated among the team to manage the lean implementation process across sites and facilitate training. This position remains until this date.

Since then, the company has been working hard to search, generate, document and easily transfer knowledge within its staff and construction sites. The regular academic benchmarking and contact, the participation and publication of papers in conferences, and constant training of the workforce are part of the internal effort on research and development. The use of A3s, pilot testing and prototypes help to document the processes in a simple and easy-to-understand way while helping its dissemination across sites. Finally, specific Kaizen events, including post-construction maintenance and occupational, safety and health Kaizens, are organised, and Hansei reflection events at the end of the projects are arranged not only for the entire company but also to the main designers, suppliers and subcontractors. 


\section{EFFORT TO STABILISE THE ENVIRONMENT}

As seen in previous literature, a priority for successful lean implementation should be to stabilise the production in the first moment, which is also the foundation of the TPS house (Liker 2004) and may be achieved at a construction company by applying the Last Planner System $^{\circledR}$. Exercising the hierarchical planning in the long, medium and short term aim to determine the pace of activities, to improve the decision making process by foreseeing and listing service constraints and to create a routine in the construction site to control daily and routine activities, providing key indicators for production and planning control. In regards to the medium and short-term planning, the main focus was to reduce the Brazilian construction industry common issue of 'making-do' (Formoso et al. 2015, 2017) and lack of terminality in services.

Making-do refers to a situation in which a task starts without having available all the inputs required for its completion, such as materials, machinery, tools, personnel, external conditions, information, etc. (Formoso et al. 2011). It resonates with Ronen's idea of a complete kit and "an incomplete kit means more labour time to finish the job, longer lead time, more work in process, reduction of throughput, poor quality and impairment of due date performance" (Ronen 1992 p. 2457).

With the proper identification of constraints, the company was able to reduce the making-do related to cutting ceramic blocks without appropriate infrastructure and outside the site's main cutting centre. Also, they reduced the unsafe burning of the top of sewer pipes (to prevent dirt from entering the previously completed sewage system) with the adoption of accessories such as PVC caps. Another issue identified through constraints removal were employees working at heights (and their related hazards) performing tasks with unsafe and adapted elements not recommended for such activities. For more details on the LPS implementation see Kemmer et al. (2008) and Valente et al. (2013, 2014).

After this stabilisation of production with better planning and control processes, the company started a second round of stabilisation with the application of other lean tools in the construction sites to motivate the engineers with practical outcomes of the lean philosophy learned through the books. These were the Kanban, the Heijunka Box, the Andon and the A3s, as seen previously (Mourão and Valente 2013).

\section{Process TRANSPaRenCy}

Over the years, other Lean tools have been adapted and incorporated into the production process and business management to improve the process transparency and enhance visual management and communication processes, such as the use of Kanbans for material flow, controlled-inventory designated floorplans, organisation of onsite warehouse in FIFO and supermarket way, production packages, prototyping with specific services, and poka-yokes. The search for transparency in the process enabled simplicity along the entire production chain and shared understanding (Valente et al. 2019).

Over the past 5 years, the company has focused on 'milk-run' routes for plumbing materials, Standardised Work and Total Productive Maintenance (TPM) (Fernandes et al. 2015). Building Information Modelling (BIM) has also been implemented for many reasons, including as a digital visualisation tool for what the company calls 'virtual gembas', where members try to anticipate mistakes or errors as early as possible in the design process. There, to see the mistake is an actual opportunity to improve the process and not to hide it. 


\section{LEAN CULTURE}

The company shares several key features for the excellence of its lean journey, such as shareholders committed to the lean construction principles and acting as motivators of a continuous improvement culture. In fact, the company persisted for five years into visiting the Toyota factory in São Paulo for benchmarking purposes. In 2018, they were one of the first businesses organisations to have that opportunity and that represented a milestone and great achievement of the company, where they could see, learn and 'drink from the source' the lean principles.

Another feature of a learning organisation is allowing people to make mistakes and learn from them. Top managers have always encouraged employees to make decisions with the following quote:

"If you make the decision and it's the right one, you get the $100 \%$ grade. If you make the decision but it's the wrong one, you get a 50\% grade. But if you just don't make a decision, you get Zero. Thus, let's make decisions and take actions, so we can, at least, learn from our mistakes and move forward".

Even before starting on its lean journey, another key feature was the company's policy to encourage continuous education among its management team by subsidising extension and postgraduate courses. Most of the team managers and staff members already had extension, postgraduate and master's courses, which facilitated the understanding of the philosophy, and contributed to the research and development environment of implementing and testing new ideas and benchmarking within the AEC industry.

This company has also been the subject of study of many academic researchers in Brazil and overseas (Ibarra et al. 2016; Rocha and Kemmer 2013). This is central to the internalised lean culture of benchmarking, continuous improvement, and prototyping, as the company obtains 'state-of-the-art' knowledge from these exchanges with academia.

To retain those highly qualified professionals and keep them motivated and engaged, the company also shows concern and respect for its employees' wellbeing providing benefits that complement their basic remuneration, such as private pension, profit sharing and health plans. For the workforce and labours, the company shows great safety and health preoccupation and has social responsibility initiatives by subsidising their home renovation (building materials and management) and encouraging healthy habits of mindfulness, meditation and exercising.

\section{BUILDING TRUST FOR FURTHER GROWTH}

Since its foundation in 1975, the company has a main principle of exceeding clients' expectations and delivering the best possible product, which is similar to the pursuit of perfection in the Toyota Production System. Thus, after all internal changes were consolidated, the company also started influencing and facilitating lean trainings for designers, suppliers and subcontractors in order to have a 'leaner' professional chain from product development to project completion. This initiative helped to build trust and team spirit with the partners, facilitating communication processes and expanding the lean culture for further company growth.

After the lean thinking was consolidated, the company felt confident to expand its horizons towards sustainability, digitalisation through BIM and social responsibility practices. The lean culture was then seen not as an end in itself, but as a means towards new challenges and achievements. Those new stimuli keep promoting continuous improvement, learning and experimenting within the company. The company invested in 
BIM technology and created virtual gembas, where, in addition to searching for conflicts in projects (clash detection), the company goes further, bringing all designers together into many sessions of compatibilising drawings, searching for better and feasible solutions and immersing into the customer view of the project and its functions.

\section{BUT THERE'S NO ROSE WITHOUT A THORN...}

Although the company's lean implementation is considered a success, the journey requires a lot of reading, understanding the philosophical assumptions, adaptation to the company's values and situational circumstances, and breaking paradigms. It is also imperative that employees realise they have to leave their comfort zone and try to build their processes from a new perspective. It may seem like it was a simple process, but it was not an easy one, as the company members were challenged to change the way they understood their own construction processes to establish a lean mindset, where the search for improvement is intrinsic and waste is now visible everywhere.

However, it is important to point out that at the beginning of the company's lean journey there were barriers to overcome, such as the workforce cultural and managerial resistance to change. Although the company had a culture fit for lean and full support from top management, the company had to let two employees go, as they were not aligned with the implementation process efforts. Both disagreed with the Last Planner implementation and the basic understandings of terminality and production control.

\section{DISCUSSION}

Throughout the years, the implementation of the lean philosophy and tools was facilitated by the company's prevailing culture fit, which already valued credibility, quality and deadline. Currently, the company's business model holds the lean thinking in its core, surrounded by three main concepts: sustainability, technology and respect for the people in the company. As seen previously, having a cultural fit that can be enriched with the lean principles, rather than directly challenged, eased the implementation process.

These findings corroborate with the work of Pekuri et al. (2012), as two strands of implementation - one holistic and the other practical—were simultaneously pursued. In many cases, the use of the lean tools and the pilot testing provided opportunities for changes in thinking and a way of developing the people and the culture altogether.

As the literature review suggested, starting the practical implementation efforts with the Last Planner ${ }^{\circledR}$ were fundamental to stabilise production and motivate construction managers with better planning and control techniques, therefore creating, according to Rodegheri and Serra (2019) the commitment feeling and a significant shared objective that requires team collaboration and growth. Adding to that, as the Lean Coordinator could manage lean efforts horizontally across sites and vertically across departments and hierarchies, a more collaborative culture emerged.

Regarding the common barriers to implementation outlined in the literature, the company was able to overcome them by prioritising the transfer and management of knowledge while also enabling experimenting with the tools. As an experiment in small scale, employees had less fear of making mistakes and could actually learn from them. The Kaizen events are also seen by employees as an opportunity to showcase good ideas for others to replicate and discuss 'not-so-good' ideas for collaborative improvement, in an empathetic exercise. In regards to knowledge creation and transfer, it is highlighted the benchmarking with the academic researchers since the beginning of the implementation, which facilitated having access to innovative techniques and solutions. 
Furthermore, in the company's strategic planning, it was decided that all knowledge generated would be transferred to the market and the academia through publications, so the company could leave a legacy and practice the true character of lean thinking.

Ratifying the statement of Richert and McGuffey (2019) about the holistic and "soft" aspects of generating enthusiasm for lean, as a family business, this company aims at creating a climate of enthusiasm and celebration of the small and big victories regarding the processes improvement, the reduction of lead times, the control of failures, and the technological innovations. In this sense, it is easier for employees to feel like their efforts are being recognised and they feel more motivated to continue giving their best.

Answering the research question, the authors believe lean maturation happens when there is an understanding that lean is not an end in itself, but a means towards a learning organisation that challenges itself by experimenting, continuously improving processes and building capabilities in its employees. As the company director states: "the celebration of victories and successful experiences is fair and necessary, however, it must serve the purpose of encouragement for the next challenge".

This company was able to mature by addressing holistic and operational lean approaches concurrently, one helping each other to grow and also by building upon successive and consolidated blocks of effort and experiences, summarised as the efforts to stabilise the environment, to promote knowledge creation and management, to increase processes transparency to enable simplicity and shared understanding, to purposefully develop a lean culture and to build trust for further growth. Table 1 summarises the building blocks of efforts and its holistic and practical features.

It is important to highlight that the first building blocks of effort helped build capacity and capabilities to the next ones to be added. The successive efforts were built upon the previous ones, but the company kept working on improving the first blocks as well. As the company built capacity, it could handle more implementation efforts. In this sense, there were no "waves of implementation", but implementation efforts to be added as the company developed its continuous improvement culture.

The authors reiterate that this is not a 'recipe for success', but what actually worked in the company's context. Regardless, these building blocks of efforts can be discussed in a conceptual way and further generalised. It is sensible that a company cannot build trust with its partners and suppliers without developing an internal culture that embraces the mistake and encourages process transparency, and to see the opportunities of improvement and to improve beyond the basics, it is fundamental to have a stable environment that enables employees to recognise variability and the effects of makingdo and other types of waste. It goes without saying that none of that is possible without knowledge creation and management.

\section{CONCLUSIONS}

Most lean implementation publications are either based on previous literature summaries, single or few construction projects, or industry surveys. Few studies present the lean implementation process from the practitioners' perspective and company-wise. This paper sought to describe how a construction company from Brazil matured from the implementation of lean operational tools to achieve excellence in the lean culture and mindset. Although there is the limitation of being a single case study, where there is no wide sample - therefore generalising the findings are very difficult, the authors believe this paper can contribute to the body of knowledge on lean implementation by depicting an account of its building blocks of efforts, such as the effort to stabilise the environment 
Achieving Excellence in Lean Implementation at Construction Companies -

A Case Study from Brazil

and to sustain a knowledge creation and management culture, and highlighting important concepts and principles, such as transparency in the process to enable simplicity and shared understanding. Besides, it substantiates the fact that there is no 'one-size-fits-all' approach and adaptation to the company values is fundamental. Hence, there is also a contribution to the practice community of lean construction.

Table 1: Building blocks of efforts in the lean implementation at the company

\begin{tabular}{|c|c|c|}
\hline Building Blocks & Holistic/soft approaches & Practical/operational approaches \\
\hline $\begin{array}{l}\text { Knowledge } \\
\text { creation and } \\
\text { management }\end{array}$ & $\begin{array}{l}\text { Culture fit - realisation that the lean philosophy was } \\
\text { aligned with the company's management style and } \\
\text { values. } \\
\text { Effort to search, generate, document and easily } \\
\text { transfer knowledge within its staff and construction } \\
\text { sites. } \\
\text { Effort to promote a research and development } \\
\text { environment that enables experimenting. }\end{array}$ & $\begin{array}{l}\text { Benchmarking with academic } \\
\text { researchers, participation in } \\
\text { conferences, creation of a free } \\
\text { corporative lean library. } \\
\text { Nomination of a Lean Coordinator. } \\
\text { Use of A3s, pilot testings and } \\
\text { prototypes. } \\
\text { Kaizen and Hansei events. }\end{array}$ \\
\hline $\begin{array}{c}\text { Effort to } \\
\text { stabilise the } \\
\text { environment }\end{array}$ & $\begin{array}{c}\text { Managerial effort to change the way the } \\
\text { improvisation is seen and done in the construction } \\
\text { sites, as to reduce making-do in the day-to-day } \\
\text { activities while still enabling improvisation for } \\
\text { developing innovative solutions within safe and } \\
\text { prototype scenarios. } \\
\text { Managerial effort to motivate site engineers to apply } \\
\text { the lean philosophy learned from the books and } \\
\text { seminars in practical pilot projects and tools. }\end{array}$ & $\begin{array}{l}\text { Adoption of the Last Planner System }{ }^{\circledast} \\
\text { Establishment of key indicators for } \\
\text { production and planning control. } \\
\text { Application of other lean tools, such } \\
\text { as Kanbans, the Heijunka Box, the } \\
\text { Andon and Total Productive } \\
\text { Maintenance (TPM). }\end{array}$ \\
\hline $\begin{array}{l}\text { Increasing } \\
\text { process } \\
\text { transparency }\end{array}$ & $\begin{array}{l}\text { A clear approach to increase transparency to enable } \\
\text { simplicity along the entire production chain and } \\
\text { shared understanding among all employees. } \\
\text { Changing the language from uncovering the } \\
\text { mistakes/errors to embracing opportunities for } \\
\text { improvement. }\end{array}$ & $\begin{array}{l}\text { Enhancing visual management and } \\
\text { communication processes through } \\
\text { Kanbans, controlled-inventory } \\
\text { designated floorplans, organisation } \\
\text { of onsite warehouse in FIFO, } \\
\text { production packages, and poka- } \\
\text { yokes. BIM as a digital visualisation } \\
\text { tool for 'virtual gembas'. }\end{array}$ \\
\hline $\begin{array}{l}\text { Developing a } \\
\text { lean culture }\end{array}$ & $\begin{array}{l}\text { Encourage continuous education to enhance the } \\
\text { academic, research and development background } \\
\text { and obtain 'state-of-the-art' knowledge from } \\
\text { exchanges with academic researches. } \\
\text { Shareholders acting as motivators of a continuous } \\
\text { improvement culture. } \\
\text { Recognition and celebration of small and big } \\
\text { victories. } \\
\text { Autonomy being encouraged among employees to } \\
\text { have them making decisions and taking responsibility } \\
\text { for processes in a learning environment. }\end{array}$ & $\begin{array}{l}\text { Subsidising undergraduate and } \\
\text { postgraduate courses. } \\
\text { Subject of study of academic } \\
\text { researchers in Brazil and overseas. } \\
\text { Recognition of employees and social } \\
\text { responsibility initiatives to improve } \\
\text { livelihood of employees and } \\
\text { encourage healthy habits of } \\
\text { mindfulness, meditation and } \\
\text { exercising. }\end{array}$ \\
\hline $\begin{array}{l}\text { Building trust } \\
\text { for further } \\
\text { growth }\end{array}$ & $\begin{array}{l}\text { Building trust and team spirit with the partners, } \\
\text { suppliers and subcontractors to facilitate } \\
\text { communication processes and expand the lean } \\
\text { culture. } \\
\text { Continuous improvement by embracing new } \\
\text { challenges and expanding its horizons towards } \\
\text { sustainability, digitalisation and social responsibility. }\end{array}$ & $\begin{array}{l}\text { The company facilitates lean } \\
\text { trainings for designers, suppliers and } \\
\text { subcontractors in order to have a } \\
\text { 'leaner' professional chain from } \\
\text { product development to project } \\
\text { completion. }\end{array}$ \\
\hline
\end{tabular}

\section{REFERENCES}

Arbulu, R., Ballard, G., and Harper, N. (2007). "Kanban in Construction." Proc. $15^{\text {th }}$ Ann. C Ann. Conf. Int. Group for Lean Construction, Virginia, USA, 1-12. 
Barbosa, G., Biotto, C., and Mota, B. (2013). "Implementing lean construction effectively in a year in a construction project." Proc. $21^{\text {st }}$ Ann. Conf. Int. Group for Lean Construction, Fortaleza, Brazil, 1017-1026.

Bygballe, L. E., and Swärd, A. (2014). "Implementing lean construction: A practice perspective." Proc. 22 ${ }^{\text {nd }}$ Ann. Conf. Int. Group for Lean Constr., Oslo, Norway, 3-14.

Chesworth, B. (2015). "Misconceptions of lean: Why implementation fails." Proc. 23 ${ }^{\text {rd }}$ Ann. Conf. of the Int'l. Group for Lean Construction, Perth, Australia, 621-630.

Creswell, J. W., and Creswell, J. D. (2018). Research Design - Qualitative, Quantitative, and Mixed Methods Approaches. SAGE Publications, London, UK.

Demirkesen, S., Wachter, N., Oprach, S., and Haghsheno, S. (2019). "Identifying Barriers in Lean Implementation in the Construction Industry." Proc. $27^{\text {th }}$ Ann. Conf. Int. Group for Lean Construction, Dublin, Ireland, 157-168.

Denscombe, M. (2010). The Good Research Guide for small-scale social research projects. Open University Press, Berkshire.

Fernandes, N.B.L.S., Saggin, A.B., Valente, C.P., Brito, F.L., and Mourão, C.A.M.A. (2015). "The Standardized Work Tool Applied to the Waterproofing Process with Acrylic Membrane." Proc. 23rd Ann. Conf. Int. Group for Lean Construction. Perth, Australia, 133-142.

Formoso, C., Bølviken, T., Rooke, J., and Koskela, L. (2015). "A conceptual framework for the prescriptive causal analysis of construction waste." Proc. $23^{\text {rd }}$ Ann. Conf. Int. Group for Lean Construction, Perth, Australia, 454-462.

Formoso, C. T., Sommer, L., Koskela, L., and Isatto, E. L. (2011). "An exploratory study on the measurement and analysis of making-do in construction sites." Proc. $19^{\text {th }}$ Ann. Conf. Int. Group for Lean Construction, Lima, Peru.

Formoso, C. T., Sommer, L., Koskela, L., Isatto, E. L., (2017). "The identification and analysis of making-do waste: insights from two Brazilian construction sites." Ambiente Construido, ANTAC, 17(3), 183-197.

Green, S. D., and May, S. C. (2005). "Lean construction: Arenas of enactment, models of diffusion and the meaning of "leanness." Building Res. and Inform., 33(6), 498-511.

Ibarra, J. V., Formoso, C. T., Lima, C., Mourão, A., and Saggin, A. (2016). "Model for integrated production and quality control: implementation and testing using commercial software applications." Proc. 24 ${ }^{\text {th }}$ Ann. Conf. Int. Group for Lean Construction, Boston, USA, 73-82.

Integris Performance Advisors. (2015). "The Four Dimensions of Lean Culture TM Enterprise Alignment.” blog.integrispa.com, <https://integrispa.com/blog/the-fourdimensions-of-lean-culture/> (May 3, 2020).

Kalyan, V., Pratap, V., and Singh, S.C. (2018). "Building a lean culture into an organization." Proc. $26^{\text {th }}$ Ann. Conf. Int. Group for Lean Constr., Chennai, India, 1101-1110.

Kemmer, S. L., Heineck, L. F. M., and Alves, T. da C. L. (2008). "Using the Line of Balance for Production System Design." Proc. $16^{\text {th }}$ Ann. Conf. Int. Group for Lean Construction, Manchester, UK, 299-308.

Koskela, L. (1992). Application of the new production philosophy to construction. Center for Integrated Facility Engineering, Stanford.

Li, S., Fan, M., and Wu, X. (2019). "Lean Construction Techniques and Individual Performance." Proc. 27th Ann. Conf. Int. Group for Lean Construction, Dublin, Ireland, 1469-1478. 
Lidelöw, H., and Simu, K. (2015). "Lean construction as an operations strategy." Proc. $23^{\text {rd }}$ Ann. Conf. of the Int'l Group for Lean Construction, Perth, Australia, 486-495.

Liker, J. K. (2004). The Toyota Way. CWL Publishing Enterprises, Madison.

Liker, J. K., Hoseus, M., and The Center for Quality People and Organizations. (2008). Toyota Culture: The Heart and Soul of the Toyota Way. McGraw-Hill Publishing.

Morrey, N., Pasquire, C., and Dainty, A. (2011). "Developing a strategy to enact lean." Proc. $19^{\text {th }}$ Ann. Conf. Int. Group for Lean Construction 2011, Lima, Peru, 530-539.

Mourão, C. A. M. A., and Valente, C. (2013). Lean \& Green Collection - C. Rolim Engenharia. C. Rolim Engenharia, Fortaleza, Brazil.

Nesensohn, C. (2017). "A Lean Construction Maturity Model for Organizations." Proc. $25^{\text {th }}$ Ann. Conf. of the Int'l Group for Lean Construction, Heraklion, Greece, 357-363.

Nesensohn, C., Demir, S. T., and Bryde, D. J. (2012). "Developing a 'True north' best practice lean company with navigational compass." Proc. $20^{\text {th }}$ Ann. Conf. Int. Group for Lean Construction, San Diego, USA.

Pekuri, A., Herrala, M., Aapaoja, A., and Haapasalo, H. (2012). "Applying lean in construction - Cornerstones for implementation." Proc. $20^{\text {th }}$ Ann. Conf. Int. Group for Lean Construction. San Diego, USA.

Poshdar, M., Gonzalez, V. A., Antunes, R., Ghodrati, N., Katebi, M., Valasiuk, S., Alqudah, H., and Talebi, S. (2019). "Diffusion of Lean Construction in Small to Medium-Sized Enterprises of Housing Sector." Proc. 27th Ann. Conf. Int. Group for Lean Construction, Dublin, Ireland, 383-392.

Richert, T. and McGuffey, J. (2019). "Enthusiasm for Lean." Proc. 27th Ann. Conf. Int. Group for Lean Construction, Dublin, Ireland, 359-368.

Robson, C. (2002). Real World Research: A Resource for Social Scientists and Practitioner-Researchers. Blackwell Publishing, Blackwell Publishing, Oxford.

Rocha, C.G. da, and Kemmer, S.L. (2013). "Managing the Information Flow in Customised Apartment Building Projects." Proc. $21^{\text {st }}$ Ann. Conf. Int. Group for Lean Construction, Fortaleza, Brazil, 279-288.

Rodegheri, P.M. and Serra, S.M.B. (2019). "Lean Construction and Maturity Models: Applying Five Methods." Proc. $27^{\text {th }}$ Ann. Conf. Int. Group for Lean Construction, Dublin, Ireland, 1081-1092.

Ronen, B. (1992). "The complete kit concept." Int. J. Production Research, Taylor \& Francis, 30(10), 2457-2466.

Valente, C.P., Brandalise, F.M.P., and Formoso, C.T. (2019). "Model for Devising Visual Management Systems on Construction Sites." Journal of Construction Engineering and Management, 145(2), 17.

Valente, C.P., Montenegro, G.A., Brito, F.L., Biotto, C.N., and Mota, B.P. (2014). "Guidelines for Developing a Line of Balance for Non-Repetitive Areas (Common Areas) at a Vertical Residential Building." Proc. $22^{\text {nd }}$ Ann. Conf. Int. Group for Lean Construction, Oslo, Norway, 763-774.

Valente, C.P., Montenegro, G.A., Brito, F.L., Biotto, C.N., Mota, B.P., and Schramm, F.K. (2013). "Benefits of batch size reduction: A case study in a residential project." Proc. $21^{\text {st }}$ Ann. Conf. Int. Group for Lean Construction, Fortaleza, Brazil.

Wandahl, S. (2014). "Lean Construction with or without Lean-Challenges of Implementing." Proc. $22^{\text {nd }}$ Ann. Conf. Int. Group for Lean Constr., Oslo, Norway, 97108. 